\title{
Fluid loading to reduce abnormalities of fetal heart rate and maternal hypotension during epidural analgesia in labour
}

\author{
K M COLLINS, D R BEVAN, R W BEARD
}

British Medical fournal, 1978, 2, 1460-1461

\section{Summary and conclusions}

Fetal heart rate (FHR) was recorded and maternal blood pressure measured in 104 patients in whom lumbar epidural analgesia was induced in labour. Fifty-one patients received an intravenous load of 11 of Hartmann's solution immediately before the epidural injection. This infusion significantly reduced the incidence of abnormalities of FHR from $34 \%$ to $12 \%$ and of maternal hypotension from $28 \%$ to $2 \%$.

We did not study mothers with pre-eclampsia and hypertension, but we conclude that there is a strong case for preloading all other mothers in whom lumbar epidural analgesia is induced in labour.

\section{Introduction}

When epidural analgesia is used in labour changes in the pattern of the fetal heart rate (FHR) sometimes occur shortly after injection of the local anaesthetic. The incidence of serious abnormalities ${ }^{12}$ varies between $4^{0}{ }_{0}{ }^{3}$ and $55 \%$, which is higher than that found in mothers receiving alternative methods of analgesia. A high proportion of abnormalities of FHR is associated with a reduction in maternal blood pressure. ${ }^{4-6}$

We have assumed that abnormalities of FHR occurring during epidural analgesia in labour are secondary to overt or concealed maternal hypotension resulting from either aortocaval compression or vasodilatation and relative hypovolaemia. Consequently, increasing the maternal blood volume by rapidly infusing fluid should reduce the incidence of both hypotension and abnormalities of FHR. We report the changes in maternal blood pressure and FHR in patients in whom epidural analgesia was induced in labour. About half the patients received a fluid load before the block.

St Mary's Hospital, London W2 $1 \mathrm{NY}$

$\mathrm{K} M$ COLLINS, MB, BS, anaesthetic registrar

D R BEVAN, FFARCS, MRCP, senior lecturer in anaesthesia

$\mathrm{R}$ W BEARD, MD, FRCOG, professor of obstetrics and gynaecology

\section{Patients and methods}

Patients were allocated randomly into control and treatment groups on the basis of their case-note number. They were excluded if they suffered from systemic disease or were more than $20 \%$ outside the predicted norms for height and weight ${ }^{7}$ or if the FHR was abnormal before induction of epidural analgesia.

Lumbar epidural analgesia was induced with $10 \mathrm{ml} 0.375 \%$ plain bupivicaine in the mother, who was supine with a pillow under her right buttock. After five minutes she was turned to her left side, where she remained throughout labour. The upper level of the block was found by pinprick after 30 minutes. Maternal brachial artery pressure was measured with a sphygmomanometer before and at five-minute intervals after the block for at least 30 minutes. Hypotension was defined as a fall in systolic blood pressure of over $20 \mathrm{~mm} \mathrm{Hg}$ and was treated with a rapid infusion of Hartmann's solution. FHR was recorded continuously with a cardiotachograph (Hewlett Packard Ltd) throughout labour in all patients. Abnormalities were classified according to the system described by Beard et al. ${ }^{8}$

Mothers in the treatment group were "preloaded" with a rapid (10-15 minutes) intravenous infusion of 11 of Hartmann's solution starting immediately before the injection of local anaesthetic. Mothers in the other group served as controls and received no additional fluids before the epidural anaesthetic.

Apgar scoring was performed on all the neonates at one and five minutes after delivery.

\section{Results}

One hundred and four patients were studied over a three-month period, 53 in the control group and 49 in the treatment group. All mothers, except for 13 in each group, were primiparae. Mean ages and weights were not significantly different between the two groups. The mean duration of labour before epidural analgesia was $7 \cdot 7$ hours in the controls and 7.4 hours in those given a fluid load. Analgesia was judged by all the patients to be satisfactory. The upper limit of the block was generally T8 or lower, except in four patients in whom it reached T6. The mean systolic blood pressure was not significantly different between the two groups before the epidural block. The blood pressure and changes in FHR after epidural analgesia was induced (table I) showed that preloading significantly decreased the incidence of maternal hypotension and abnormal FHR.

Table II shows the types of FHR abnormality found in the two groups. In the controls most of the abnormalities were transient, but in four subjects the abnormality lasted more than 30 minutes and in two persisted until delivery several hours later. Eight of the 18 abnormalities were associated with maternal hypotension. In all subjects the hypotension developed within five to 15 minutes of the bupivicaine injection, and resolved within 20 minutes after rapid infusion of Hartmann's solution. The Apgar score at one minute was above 7 in all the neonates except two, one of whom was delivered by

TABLE I-Clinical data and incidences of maternal hypotension and abnormality of fetal heart rate (FHR) after epidural analgesia

\begin{tabular}{|c|c|c|c|c|c|c|c|c|}
\hline \multicolumn{3}{|c|}{ Group } & \multirow{2}{*}{$\begin{array}{c}\begin{array}{c}\text { No in } \\
\text { group }\end{array} \\
53 \\
49\end{array}$} & \multirow{2}{*}{$\begin{array}{l}\begin{array}{c}\text { Mean }(: S D) \\
\text { age in years }\end{array} \\
26 \cdot 8 \pm 5 \cdot 5 \\
26 \cdot 6 \pm 5 \cdot 5\end{array}$} & \multirow{2}{*}{$\begin{array}{c}\begin{array}{c}\text { Mean }(\leq \mathrm{SD}) \\
\text { weight }(\mathrm{kg})\end{array} \\
\begin{array}{c}71 \cdot 0 \\
69 \cdot 8\end{array} \mathbf{1 1 \cdot 3}\end{array}$} & \multirow{2}{*}{$\begin{array}{c}\begin{array}{c}\text { Mean }(\mathrm{SD}) \\
\text { systemic BP before } \\
\text { block }(\mathrm{mm} \mathrm{Hg})\end{array} \\
116 \cdot 6: 11 \cdot 4 \\
112 \cdot 8 \pm 11 \cdot 8\end{array}$} & \multirow{2}{*}{$\begin{array}{c}\text { No }\left("{ }^{\prime \prime}\right) \text { with } \\
\begin{array}{c}\text { FHR abnormality } \\
\text { after block }\end{array} \\
\begin{array}{c}18(34) \\
6(12)\end{array}\end{array}$} & \multirow{2}{*}{$\begin{array}{c}\begin{array}{c}\text { No }(0) \text { with } \\
\text { hypotension } \\
\text { after block }\end{array} \\
15(28) \\
1(2)\end{array}$} \\
\hline $\begin{array}{l}\text { Control } \\
\text { Fluid load : }\end{array}$ & $\begin{array}{l}. \\
.\end{array}$ & $\begin{array}{l}\cdots \\
\cdots\end{array}$ & & & & & & \\
\hline $\begin{array}{ll}\varkappa^{2} & \ldots \\
\mathbf{P} & \cdots\end{array}$ & 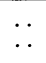 & $\therefore$ & & & & & $\begin{array}{l}5 \cdot 1 \\
0 \cdot 025\end{array}$ & $\begin{array}{c}11 \cdot 2 \\
0.005\end{array}$ \\
\hline
\end{tabular}

$\mathrm{BP}=$ Blood pressure 
TABLE II-Abnormalities of fetal heart rate in 18 patients in control group and six given fluid load

\begin{tabular}{|c|c|c|c|c|c|c|c|}
\hline \multirow{2}{*}{\multicolumn{2}{|c|}{ Group }} & \multicolumn{3}{|c|}{ Deceleration } & \multirow{2}{*}{$\begin{array}{c}\text { Loss of } \\
\text { beat-to-beat } \\
\text { variability }\end{array}$} & \multirow{2}{*}{$\begin{array}{c}\text { Baseline } \\
\text { bradycardia }\end{array}$} & \multirow{2}{*}{$\begin{array}{l}\text { Baseline } \\
\text { tachycardia }\end{array}$} \\
\hline & & Early & Late & Variable & & & \\
\hline $\begin{array}{l}\text { Control }(n=18) \\
\text { Fluid load }(n=6) \ldots\end{array}$ & $\begin{array}{l}\cdots \\
\cdots\end{array}$ & $\begin{array}{r}10 \\
3\end{array}$ & 1 & 1 & $\begin{array}{l}5 \\
2\end{array}$ & 1 & 1 \\
\hline
\end{tabular}

caesarean section under general anaesthesia for failure to progress and the other by Kielland's forceps for fetal distress in the second stage.

In the patients given fluid load all the FHR abnormalities had resolved within 30 minutes. None was associated with maternal hypotension. All neonates in this group had an Apgar score of over 7 at one minute except one who was delivered by caesarean section under general anaesthesia. One patient in this group became hypotensive without any concurrent abnormal FHR.

Seventeen patients in each group received an infusion of oxytocin (Syntocinon), but the incidence of maternal hypotension or abnormal FHR was not significantly different between those who had and those who had not received the infusion.

Patients who received a fluid load continued to be preloaded with $500 \mathrm{ml}$ of Hartmann's solution for each top-up dose of 6-8 $\mathrm{ml}$ of $0.375 \%$ bupivicaine. As so many variables changed before each topup, however, (infusion, volume of bupivicaine, state of hydration, abnormalities of FHR not obviously related to the epidural analgesia) and the number of patients was relatively small, we felt that it would be incorrect to draw conclusions about preloading top-ups, although we gained the impression that the control group had a higher incidence of FHR abnormalities and hypotension.

\section{Discussion}

The results of this study shows that a significant reduction in the incidences of maternal hypotension and abnormalities of FHR after epidural analgesia in labour may be achieved by the prior administration of 11 of Hartmann's solution. Previous studies have indicated the safety of epidural analgesia in labour in terms of Apgar score and perinatal mortality. Apgar scores are usually high and the incidence of fetal metabolic acidosis low when epidural analgesia is compared with other methods of obstetric analgesia. ${ }^{9-11}$ Most of the episodes of abnormal FHR in the control group and all those in the group given a fluid load in our study were transient, and the importance of such abnormalities must not be exaggerated. Nevertheless, fetal monitoring and early treatment of serious abnormalities does reduce overall fetal mortality. ${ }^{12}$ Consequently, effective prophylaxis would be a useful addition to safe obstetric practice.

Various treatments have been successfully used to prevent maternal hypotension during labour. The biochemical and clinical states of the neonates may be improved by fluid loading during spinal analgesia for caesarean section. ${ }^{13} \mathrm{~A}$ similar beneficial effect of a lateral tilt during general anaesthesia for operative delivery has been described in several studies. ${ }^{14-18}$ The safety of preloading for the mother and fetus has been shown. ${ }^{19}$ In the present study no deleterious effects were seen in the mother, although systolic blood pressure increased by more than $20 \mathrm{~mm} \mathrm{Hg}$ in $27^{\circ}{ }_{0}^{\circ}(14 / 51)$ after the infusion. This increase was transient, lasting 15 minutes, and due to rapid intravascular volume expansion and subsequent extravascular equilibration. The FHR in one patient showed a bradycardia followed by a tachycardia during the infusion, although this reverted to normal within a few minutes.

The relation between maternal hypotension and FHR abnormality was inconstant, although fluid loading reduced the incidence of both. This was probably due in part to varying degrees of uteroplacental reserve and aortocaval compression even in the lateral position. None of the three patients with abnormal FHR in the group given fluid loads showed any hypotension. It is tempting to speculate that the cause of these changes was unrelated to impaired uteroplacental perfusion and was either imminent fetal distress from other reasons or fetal toxicity to the local anaesthetic. Fetal toxicity seems unlikely as the direct effect of bupivicaine on the cardiovascular system of the fetus is negligible with the dose used during the present study. ${ }^{20}$

The number of patients in this study precludes any conclusion about mothers with pre-eclampsia and hypertension, but the results suggest a strong case for preloading all other mothers in whom lumbar epidural analgesia is induced in labour.

We should like to thank our colleagues in both departments for their co-operation, and Miss Angela Colbran for her invaluable secretarial help.

\section{References}

${ }^{1}$ Hon, E H, and Quilligan, E J, Clinical Obstetrics and Gynecology, 1968, 2, 145.

2 Thomas, G, British fournal of Obstetrics and Gynaecology, 1975, 82, 121.

${ }^{3}$ Joupilla, $\mathrm{P}$, et al, British fournal of Obstetrics and Gynaecology, 1977, 84, 481.

${ }^{4}$ Wingate, M B, et al, American fournal of Obstetrics and Gynecology, 1974, $119,1101$.

${ }^{5}$ Prinz, J L, and McMaster, R H, Current Researches in Anesthesia and Analgesia, 1972, 51, 876.

${ }^{6}$ Schifrin, B S, fournal of Obstetrics and Gynaecology of the British Commonwealth, 1972, 79, 332.

7 Gilmer, $\mathbf{M}$, personal communication.

${ }^{8}$ Beard, R W, et al, fournal of Obstetrics and Gynaecology of the British Commonwealth, 1971, 78, 865.

${ }^{9}$ Potter, N, and Macdonald, R D, Lancet, 1971, 1, 1031.

10 Romeine, J C, Clarke, R B, and Brown, W E, fournal of Obstetrics and Gynaecology of the British Commonwealth, 1970, 77, 722.

${ }_{11}$ Scanlon, J W, et al, Anesthesiology, 1974, 40, 121.

12 Johnstone, F D, Campbell, D M, and Hughes, G J, Lancet, 1978, 1, 1298.

${ }_{13}$ Marx, G F, Cosmi, R V, and Wollman, S B, Current Researches in Anaesthesiology and Analgesia, 1969, 48, 986.

${ }^{14}$ Clark, R B, Thomson, D S, and Thompson, C H, Anesthesiology, 1976, 45, 670.

15 Weaver, J B, Pearson, J F, and Rosen, M, Anaesthesia, 1975, 30, 752.

${ }^{16}$ Godlin, R C, Obstetrics and Gynecology, 1971, 37, 702.

17 Baheti, D K, et al, Anaesthesia, 1975, 30, 396.

${ }_{18}$ Downing, J W, et al, Anaesthesia, 1974, 29, 696.

19 Wollman, S B, and Marx, G F, Anesthesiology, 1968, 29, 374.

${ }^{20}$ Ralston, D H, and Shider, S M, Anesthesiology, 1978, 48, 34.

(Accepted 3 October 1978)

ONE HUNDRED YEARS AGO The fees of the physician are honoraria; those of the surgeon being, however, recoverable by, and the occasional subject of, lawsuits. It is somewhat disgusting to the professional mind to have to discuss fees at all. This sentiment is materially expressed by the piece of paper in which the fee is habitually wrapped, and the tacit manner in which it is paid. But advantage should not be taken of this to attempt to bind professional men to the uniform acceptance of an insufficient payment for services of very various value. It has repeatedly been shown that the guinea fee has become a traditional fiction; and, subject to the condition that there shall be no surprise, it may be asked why every consultant shall not have the same right in medicine as in other professions to value his own services at his own tariff-leaving it free to those who know the cost beforehand to consult him or not as they please. Far from general practitioners being injured by high consulting fees, they are, in fact, benefited by them; and the talent of younger men, who are properly and necessarily willing to accept lower fees, will always meet the needs of limited incomes. (British Medical fournal, 1878.) 